\title{
Causal Factors of Anxiety Symptoms in Children
}

Valadão Dias $\mathrm{F}^{1^{*}}$, Juliana Álvares Duarte Bonini Campos ${ }^{2}$, Raquel V. Oliveira ${ }^{4}$, Rosário Mendes ${ }^{3}$, Isabel Leal ${ }^{1}$ and Joao Maroco ${ }^{1}$

${ }^{1}$ William James Center Research (WJCR), Lisboa, Portugal

${ }^{2}$ UNESP-Paulista State University -School of Dentistry of Araraquara, Department of Social Odontology, Araraquara, Sao Paulo, Brazil

3/SPA-University Institute, Portugal

${ }^{4}$ Florida State University, College of Criminology and Criminal Justice, Tallahassee, Florida, USA

"Corresponding author: Filomena Valadão Dias, Department of Clinical Psychology, William James Center Research-WJCR, ISPA-University Institute, Rua Jardim do Tabaco, 34, 1149-041 Lisboa, Portugal, Tel: 00351 966876195; E-mail: fdias@ispa.pt

Receiving date: June 07, 2016, Accepting date: June 19, 2016, Publishing date: June 25, 2016

Copyright: @ 2016 Valadão Dias F, et al. This is an open-access article distributed under the terms of the Creative Commons Attribution License, which permits unrestricted use, distribution, and reproduction in any medium, provided the original author and source are credited.

\begin{abstract}
Aim: The present work aimed to investigate the impact of the child's cognitions associated with ambiguous stimuli that refer to anxiety, both parents' fears and anxiety, and parents' attributions to the child's interpretations of ambiguous stimuli on child anxiety. The influence of parental modelling on child's cognitions was also analyzed.

Method: The final sample was composed of 111 children (62 boys; 49 girls) with ages between 10 and 11 years $(M=10.6, S D=0.5)$ from a community population, and both their parents. The variables identified as most significant were included in a predictive model of anxiety.

Results: Results revealed the children's thoughts (positive and negative) related to ambiguous stimuli that describe anxiety situations. Parents' fears and mothers' anxiety significantly predict children's anxiety. Those variables explain $29 \%$ of the variance in children general anxiety. No evidence was found for a direct parental modeling of child cognitions.

Conclusion: Children's positive thoughts seem to be cognitive aspects that buffer against anxiety. Negative thoughts are vulnerability factors for the development of child anxiety. Parents' fears and anxiety should be analyzed in separate as they have distinct influences over children's anxiety. Mothers' fears contribute to children's anxiety by reducing it, revealing a possible protective effect. It is suggested that the contribution of both parents' fears to children's anxiety may be interpreted acknowledging the existence of "psychological and/or behavioral filters". Mothers' filters seem to be well developed while fathers' filters seem to be compromised. The contribution of mothers' anxiety (but not fathers' anxiety) to children's anxiety is also understood in light of the possible existence of a "proximity space" between the child and parents, which is wider with mothers than with fathers.
\end{abstract}

Keywords: Casual relation; Child anxiety; Mother and father; Fear and anxiety; Cognitions

\section{Introduction}

Current literature related to childhood anxiety is unlimited. It is assumed that the healthy manifestation of anxiety is a protective factor and an indicator of children's normal development [1-4]. However, the idea that anxiety during childhood and adolescence is not always transitory and that, in many cases, it leads to pathological anxiety and other disorders that may persist into adulthood raises a great concern among researchers and clinicians [5,6]. It is assumed that many children who suffer from one of the anxiety disorders will suffer from this disorder from time to time for the rest of their lives [7]. It is estimated that approximately 5 to $20 \%$ of children and adolescents suffer from any anxiety disorder, which may have a severe impact on their lives [8]. Although these consequences are well known, theories and interventions with children under 12 years old are far below from those in the field of adults' anxiety [9].

Cognitive-behavioral theories have emphasized the impact that negative or dysfunctional beliefs systems may have in the origin, development and maintenance of anxiety disorders [10]. The biased interpretation of ambiguous material is a cognitive process that has been systematically associated with children's anxiety [11-16]. The dysfunctional and maladaptive thoughts represent the cognitive distorted products that are considered a result of the individual's biased interpretations of ambiguous situations as negative or threatening $[10,17]$. Several studies have investigated these cognitive products [12,18-24].

Despite the numerous studies undertaken to examine the relationship between children anxiety and processing biases and/or cognitive products, their inconsistent and sometimes contradictory results have raised many doubts and questions that are presented in literature $[14,17,18,24]$. Thus, assuming the relation between cognition and the understanding of the aetiology, development and maintenance of anxiety disorders, there is a need to seriously consider the cognitive aspects related to children's anxiety taking into account the child's knowledge and the child's cognitive development, context, and characteristics associated to the child's age when studying this phenomenon $[9,10,15,17,25,26]$.

In this sense, some studies have highlighted the importance of analyzing the contents of children's thoughts related to ambiguous 
stimuli that refer to anxiety issues $[12,26]$. These studies demonstrated the existence of beliefs and perceptions of children concerning themselves (Self) and their ability to cope with situations. These analyses comprise more aspects than the usual contents found in literature regarding the perception and interpretation of situations as threatening or non-threatening. Therefore, the relation between children's anxiety and the perceptions and beliefs that their thoughts reveal has been stated in some studies [12,16,27]. It is important to note that in Bögels and Zigterman's [12] study, the biases in children's interpretations were more related to an underestimation of their own ability to cope with the situation than with an overestimation of the danger of the situation. Similar results were found in Waters et al. [16] as a cognitive behavioral intervention had positive effects only in children's beliefs about their ability to influence situations, but had no influence on children's perception of threat. Creswell and O'Connor [14] also assume the relevance of children's beliefs about their inability to influence situations while responding to ambiguous stimulus, and emphasize their relation with children's tendency to anticipate negative emotional reactions which, according to the authors, is associated with an anticipated level of distress [14]. The authors analyzed the anticipated level of distress and the threat interpretation biases of children aged between 10 and 11 from a community sample. Again, the results revealed the existence of a relation between children's anxiety and their beliefs about their inability to influence situations and the corresponding anticipated negative emotional reactions. The results also showed that the interpretation of threat was significantly related to anxiety in the second and third moments, but anticipated distress was significantly associated with anxiety at all assessment times [14].

In line with these findings and to better understand the cognitive characteristics of anxiety in childhood [14], have recently suggested that anxiety may be preceded by a state of "general non-specific wariness or inhibition" (p. 200) associated with the child's view that he/she will not be able to cope, which subsequently influences the construction of explanations about the child's internal experiences; these experiences will later contribute to maintain anxiety. Another work from Creswell et al. [27] proposed that children's interpretation of ambiguous scenarios would be stable over the three times of assessment and would predict anxiety symptoms in children. Results revealed that children's interpretation of threat was not a significant or a longitudinal predictor of children's anxiety at any time point. However, children's distressed cognitions predicted children's anxiety scores in the last assessment moment. The authors suggested that specific cognitive themes may have different associations with anxiety, and pointed that further research may contribute to understand this issue.

Although it is generally assumed that information processing abnormalities play a role in the maintenance and even exacerbation of anxiety problems, most studies that investigate these variables do not analyze the cause-effect relationship between them [28]. When this relationship is studied, the focus relies on the biased perception of threat. In one study that aimed at examining the temporal stability of threat perception abnormalities and anxiety symptoms, no evidence was found for a direct prospective connection between those two variables [29]. The study of Muris and Field [28] along with the results of Muris et al. [29], in which they analyzed children's perception and interpretation of anxiety-related physical symptoms, suggest that the relation between cognitive biased processing in children is more explained by the child's characteristics to cope with the situations than by a focus on the threat presented by situations [30].
Warren et al. [31] investigated whether certain specific internal representations of the self and of the experiences will predict later childhood anxiety. The authors developed a prospective study with 5year old children from a community sample and used their story-stem play narratives. Contents related to separation, to their competence and to general negative expectations about oneself and others (e.g. not seeking help from their parents; ending stories negatively) were found and analyzed. The results demonstrated that children's negative expectations predicted later anxiety and constitute a risk factor or an enhancer mechanism for the development of later anxiety [31].

In order to explore the contents of children's thoughts related to ambiguous stimuli that describe situations associated with childhood anxiety, Valadão Dias et al. [26] analyzed the contents of positive and negative thoughts in a community sample of children with 10 and 11 years. Several contents were observed, including contents related to the children's view of their (in)ability or (in)competence to cope and influence situations. A high number of contents were related to the expression of emotions, i.e. emotional experiences in a linguistic form [32], which indicates the need to consider these contents when trying to understand the cognitions related to anxiety.

Based on the results of all the previous studies, Valadão Dias et al. [26] confirmed the need to examine the causal relation between positive and negative thoughts and children's anxiety, and also the likely contribution of negative thoughts to the development of more symptoms of anxiety or even to anxiety disorders. On the other hand, it is also important to analyze the contribution of positive thoughts to the promotion of an adequate management of anxiety symptoms, meaning that these thoughts may be considered as protective factors that may optimize the child's development [26].

Despite the importance of genetic factors, environmental variables have also been associated with childhood anxiety $[33,34]$. Since anxiety disorders in children have been identified as a significant problem, the converging areas of research suggest that parents play an important role in the development and maintenance of childhood anxiety $[33,35]$.

The literature has described the association of parents' anxiety with children's anxiety, concluding that there is a strong association between these two variables [36]. Parents' anxiety is the factor that most contributes to children's anxiety [37]. Gifford et al. [38] found that mothers' anxiety was significantly correlated with children's anxiety. However, there is not a consensus regarding the existence of a significant association between parents' anxiety and children's anxiety, because inconsistent results have been found in other studies $[39,40]$. More studies are needed to analyze the causal relation between these variables and the impact of parents' anxiety on children's anxiety.

On the other hand, the results of Bögels et al. [41] revealed a significant association between mothers' fears and children's anxiety, but there was not a significant association between parents' fears and children's anxiety. Muris et al. [42] found a significant association between parents' anxiety and children's anxiety, but only mothers' fears were associated with children's fears and this relation depended on the expression or not of mothers' fears. These conclusions show that the influence of parents' anxiety and fears on children's anxiety should be clarified, anxiety and fears should be assessed as independent concepts, and even if excessive fear and anxiety are faced as characteristics of anxiety disorders, their definitions also explain their differences, i.e. "fear is the emotional response to real or perceived imminent threat, whereas anxiety is anticipation of future threat" (American Psychiatric Association, 2013, p. 180). 
In this sense, besides parents' anxiety, that is generally seen as a risk factor for child anxiety disorders (Bögels and Brechman-Toussaint [43]); parents' fears seem to have some relation with children's anxiety. Besides the possible direct contribution of parents' anxiety and fears to children's anxiety, other mechanisms by which parents convey their anxious predisposition or disorder to their children are not well understood [43].

Parents often provide most of the learning experiences to children throughout their development, but the degree to which they provide anxiety-related learning experiences may be a significant factor to the development of children's anxiety [44]. In this sense, some authors emphasize Bandura's social learning theory and parents' possible role in modelling child's anxiety by the display of visual signs of fear in the child's presence and/or by verbally expressing information about their own anxiety directly to the child, or even when talking to themselves or to someone else about it [44]. According to Bandura [45], there is evidence that children may learn fear reactions by observing those reactions in other people (e.g. parents, siblings, peers).

Besides this learning process that is focused on observation, Rachman [46] stated that there is a relation between anxiety and the cognitive aspects that refer to negative verbal information. Thus, parents may model not only the child's anxious behaviors, but also the child's anxious cognitions (e.g. transmission of threat-related information, negative expectations and/or perceived lack of child's ability [41,44].

Pioneer studies have analyzed parental modelling concerning children's anxiety and cognitions related to ambiguous stimuli $[11,13]$. The authors intended to investigate if anxious children, like anxious adults, presented biased threat interpretations [11] or cognitive biases related to anxiety [13], and if parents influenced their children's cognitions related to ambiguity $[11,13]$.

Barrett et al. [11] concluded that among three groups of children (i.e., anxious group, oppositional group and non-clinical group) the non-clinical group presented the lowest threat interpretation scores and the oppositional group had the highest scores. However, when analyzing the relation between threat interpretations and avoidance, and aggressive plans of action, the only significant differences were found between the anxious and the oppositional groups. Results revealed that oppositional children were less likely than anxious children to respond to threat interpretations with avoidant responses. Parental influence was assessed through the plans of action (what they would do in that situation) presented by children after discussion of the previous action plans with parents. There was a large increase in the percentage of anxious children choosing an avoidant solution.

In Chorpita et al. [13]; children with higher anxiety trait were more prone to present anxious cognitions, which are probably influenced by their parents' negative verbalizations. The results also suggested that parents do not have an equal pattern of influence over their children's anxious cognitions, i.e., fathers' verbalizations seemed to account more for that effect than mothers' verbalizations.

In this sense, children's cognitions associated with ambiguous stimuli related to anxiety seem to be liable to parents' intervention and their modelling of children's cognitions $[13,35]$; parents' own anxiety contributes to the modelling of children's anxiety. If parents are anxious, they may convey more anxious information to the child [15] as well as anxiety-related learning experiences [44].
Following the needs identified in literature, the present study sought to advance previous research and knowledge on children's vulnerability to the development of anxiety by examining the impact of the following aspects on children's anxiety symptoms: (1) the child's positive and negative cognitions associated with ambiguous stimuli that refer to anxiety, (2) both parents' fear and anxiety; (3) parents' attributions of the child's interpretations of ambiguous stimuli, and (4) to analyze the influence of parental modelling on children's cognitions. In order to provide relevant information to the understanding of childhood anxiety, as proposed in literature the current study used a community sample $[35,39,44]$ and only families with both parents' participation were considered for analysis $[35,47,48]$.

\section{Method}

\section{Participants}

A total of 478 children and their parents from a community sample from Terceira Island - Azores/Portugal were invited to participate in the study. Of these, 302 families (child and parents) agreed to participate in the study. A day and time were scheduled for each family's participation/interview. Due to scheduling issues, 24 families were not able to participate. The sample was now composed of 278 families. Informed consent was obtained from all participants, including the children's informed consent.

The inclusion criteria for participation in the study were: i) age between 10 and 11 years, ii) normal development, and iii) a complete interview. After this stage, four families were excluded, because two children had been diagnosed with significant developmental problems; two other children did not complete the interview. Both parents had to participate and this happened in 171 cases. Parents also had to complete the State-trait Anxiety Inventory [49]. As this questionnaire was introduced after the beginning of the data collection, only 330 subjects (111 families) were included in the study. The final sample was composed of 111 families, with 62 boys and 49 girls, who had a mean age of 10.6 years $(\mathrm{SD}=0.5)$ and attended middle school $(5$ th and 6th grades). In every family, parents were the child's mother and father, and they both lived together. The group of fathers had a mean age of 41.9 years $(\mathrm{SD}=4.9), 98.2 \%$ of them were employed, $12.7 \%$ had attended tertiary education, $10.0 \%$ had concluded the secondary school, and $77.3 \%$ had completed the 9 th grade or a lower educational level. The children's mothers had a mean age of 39.4 years $(\mathrm{SD}=5.4)$, $74.8 \%$ were employed. In terms of education levels, $22.7 \%$ of the mothers had attended tertiary education, $21.6 \%$ had concluded secondary education, and $55.7 \%$ had completed the 9th grade or a lower educational level. Mothers have more academic qualifications than fathers $(\chi 2(3)=11.84 ; \mathrm{p}=0.008)$.

\section{Instruments}

The instruments for data collection included a socio-demographic questionnaire for each participant (child, mother, father); the Portuguese version of the Screen for Child Anxiety Related Emotional Disorders - Revised Version (SCARED-R) [50]; the Portuguese version of the Fear Survey Schedule III (FSS III) [51]; the State-Trait Anxiety Inventory (STAI-Y) [49]; and the Portuguese version of the Nine Ambiguous Stories [12].

The Portuguese version of the SCARED-R used in this study was proposed and validated in a previous study [52] for the population from which the sample derived. The psychometric characteristics of 
Page 4 of 11

the scale were good $(\chi 2 / \mathrm{df}=2.5 ; \mathrm{CFI}=0.92 ; \mathrm{GFI}=0.92$; $\mathrm{RMSEA}=$ $0.04 ; \alpha=0.70-0.88)$. This instrument aims to estimate children's anxiety by measuring their anxiety symptoms. The scale has 9 subscales: Separation Anxiety Symptoms including School Phobia symptoms; Generalized Anxiety symptoms; Social Phobia/Anxiety symptoms; Panic Disorder symptoms; Obsessive-Compulsive Disorder symptoms; Traumatic Stress Disorder symptoms; and, Specific Phobias symptoms (i.e., animal phobias; situational-environmental phobia; bloodinjection-injury phobia). Children are asked to indicate how frequently they have each symptom on a three-point scale: 0 (almost never); 1 (sometimes); 2 (often). The SCARED-R total is calculated by adding the responses given to the items. Scores range from 0 to 114 and higher scores reflect higher levels of anxiety symptoms [50,52]. In the present study, SCARED-R total score was used to analyze the contribution of the other variables of the study to children's anxiety symptoms.

The Portuguese version of the FSS III was proposed and validated in a previous research [53] for the population under study. This instrument is used to estimate adults fears. The properties of the scale were $\operatorname{good}\left(\chi^{2} / \mathrm{df}=3.4\right.$; CFI $=.90$; GFI $=.90$; RMSEA $=.05 ; \alpha=.72-$. 86). The FSS III has 33 Likert-type items with 5 points $(0=$ no fear at all; 1 = little fear; 2 = some fear; $3=$ fear; and $4=$ much fear), which are distributed across five dimensions: Social Anxiety; Agoraphobia; Fear of Bodily Injury, Death and Illness; Fear of Display to Aggressive Scenes; and Fear of Harmless Animals. The score of General Fear is the result of an algorithm that considers each item/factor's weight according to the 2 nd order factor of the hierarchical model proposed by Valadão Dias et al. [53].

The State-Trait Anxiety Inventory (STAI-Y) [49] is used to estimate adults' anxiety level. This instrument is composed of two independent scales that measure the state and trait anxiety. For the current work, only the data from the Trait Anxiety Scale (STAI Form Y-2) were used. The STAI Form Y-2 scale is composed of 20 sentences that assess how people generally feel. The answers are chosen in a 4-point Likert-type scale ( $1=$ almost never; $2=$ sometimes; $3=$ often; $4=$ almost always). A Confirmatory Factor Analysis was made to verify the inventory's validity and reliability in the present sample. Eight items (24, 28, 29, 32, $35,37,38,40)$ were removed $(\chi 2 / \mathrm{df}=2.3$; CFI $=0.95$; GFI $=0.93$; RMSEA $=.06 ; \alpha=.89)$. The final anxiety score for each parent was estimated based on the mean obtained from the answers to the 12 questions.

The Nine Ambiguous Stories (male and female versions) were developed and validated by Bögels and Ziterman [12]. They present nine potentially threatening situations to children, which are ambiguous because their outcome is uncertain. Three of the stories describe generalized anxiety situations, three refer to separation anxiety situations, and three describe social anxiety situations. The ambiguity of the scripts was further validated by the fact that children from normal samples gave positive, neutral and negative responses to the same stimuli [12].

The Nine Ambiguous Stories [23] were adapted and translated according to the recommended standards for cross-cultural research [54]. The nine stories were recorded into audio format (male and female versions). Another audio recording was created with only three of the nine stories. These stories were selected according to a previous discussion with the author of the stories. Thus, the criterion to select the three stories was the type of anxiety that would lead to higher levels of anxiety.

\section{Procedure}

All interviews were conducted by the main researcher. In each interview, the researcher met the family on a room (room 1) to explain the study's goals, clarify the family's doubts, ensure data confidentiality and anonymity and ask written informed consent. After this moment, parents went to another room (room 2). In room 1, the child completed a socio-demographic questionnaire and the SCARED-R. Then, the child was instructed to imagine that each situation described in each story would actually happen to her/him, and listened to the Nine Ambiguous Stories. After each story, the researcher asked the child "What would you think if you were in this situation?" The researcher wrote down the child's answer verbatim.

In room (room 2), parents completed the socio-demographic questionnaire and the FSS III and also listened to an audio recording of the nine stories. At the end of each story, the research assistant asked "What would a child think in this situation?" and wrote down what the father and the mother said (verbatim). The instructions given were proposed by Bögels et al. [41]. As in their study by Bögels et al. [41], parents were instructed to indicate what children in general, not their own child, would think in the situation. This procedure was intentional, because it gives access to the attributions of parents about children (not their own children), based on parents' own interpretation. These thoughts were designated throughout the present study as attributions, i.e. parents' verbalizations indicating what they think a child would think about a situation.

After this stage, parents joined the child on the other room. Then, parents and child were asked to listen together an audio-tape with only three of the nine stories. After each story, the researcher instructed the parents to discuss with their child the best way to think about the situation described in the story while the researcher left the room for 5 minutes.

After this task, parents completed the State-Trait Anxiety Inventory (STAI-Y) in room 2. In room 1, the child listened to the same three stories again, and the researcher repeated the previous question and wrote down the child's answer. In the end, families were debriefed, and some aspects about the meaning of the study were clarified. The duration of the entire process was approximately 2 hours for each family.

\section{Data Analysis}

The classification of children's thoughts and parents' attributions (Thoughts/Attributions) followed the definitions of the categories validated for the population under study [24]. The analysis considered the count of children's negative thoughts $\left(\mathrm{N}_{\mathrm{TC}}\right)$, children's positive thoughts $\left(\mathrm{P}_{\mathrm{TC}}\right)$, mothers' negative attributions $\left(\mathrm{N}_{\mathrm{AM}}\right)$, fathers' negative attributions $\left(\mathrm{N}_{\mathrm{AF}}\right)$, mothers' positive attributions (PAM) and fathers' positive attributions $\left(\mathrm{P}_{\mathrm{AM}}\right)$ about the nine stories. The counts of children's thoughts about the three stories used for discussion were analyzed in terms of negative thoughts $\left(\mathrm{NT}_{\mathrm{CD}}\right)$ and positive thoughts $\left(\mathrm{PT}_{\mathrm{CD}}\right)$.

The Pearson Correlation matrix ( $r$ ) concerning fears, parents' anxiety, mothers' and fathers' thoughts, children's thoughts and general childhood anxiety symptoms was estimated. A multiple linear regression model was developed using Structural Equation Modelling (SEM). The estimation of parameters was based on the Maximum Likelihood method, the dependent variable was general childhood anxiety (total score) and the independent factors were gender, parents' 
Page 5 of 11

fear and anxiety (total scores for both), parents' attributions and children's thoughts.

Then, the contributions of parents' attributions, fear and anxiety to the difference $(\Delta)$ between children's thoughts pre- and post discussion with parents were evaluated. Four models of multiple linear regressions with these variables were built, using SEM. A significance level of $5 \%$ $(\alpha=.05)$ was used to make a decision on which factors contributed most to the difference in children's thoughts. All statistical analyses were performed using SPSS Statistics (v. 21, An IBM Company) and SPSS AMOS (v.21, An IBM Company).

\section{Results}

The Pearson Correlation matrix ( $r$ ) of the target variables is presented in Table 1.

\begin{tabular}{|c|c|c|c|c|c|c|c|c|c|c|c|}
\hline \multirow{3}{*}{$r(p)$} & & \multicolumn{6}{|c|}{ Thoughts and $d^{\#}$ Attributions } & \multicolumn{2}{|c|}{ Fear \#\# } & \multicolumn{2}{|c|}{ Anxiety \#\# } \\
\hline & & \multicolumn{6}{|c|}{$(\mathrm{T})(\mathrm{A})$} & \multicolumn{2}{|l|}{ (F) } & \multicolumn{2}{|l|}{ (A) } \\
\hline & & $\mathrm{PA}_{\mathrm{F}}$ & $\mathrm{PA}_{\mathrm{M}}$ & $\mathrm{PT}_{\mathrm{C}}$ & $\mathrm{NA}_{\mathrm{F}}$ & $N A_{M}$ & $\mathrm{NT}_{\mathrm{C}}$ & $\mathrm{FSS}_{\mathrm{F}}$ & $\mathrm{FSS}_{\mathrm{M}}$ & $S T A I_{F}$ & $\mathrm{STA}_{\mathrm{M}}$ \\
\hline \multirow[t]{2}{*}{$\mathbf{T}$} & \multirow{2}{*}{$\mathrm{PA}_{\mathrm{F}}$} & \multirow{2}{*}{1} & $.22^{*}$ & -0.02 & $-.40^{* *}$ & $-.24^{*}$ & 0.12 & 0.07 & -0.19 & 0.07 & $-.23^{*}$ \\
\hline & & & $(0.02)$ & $(0.84)$ & $(<.001)$ & $(0.01)$ & $(0.21)$ & $(0.49)$ & $(0.05)$ & $(0.49)$ & $(0.02)$ \\
\hline & \multirow{2}{*}{$\mathrm{PA}_{\mathrm{M}}$} & \multirow{2}{*}{ - } & \multirow{2}{*}{1} & $.28^{* *}$ & -0.15 & $-.201^{*}$ & 0.01 & -0.02 & -0.13 & -0.06 & $-.210^{*}$ \\
\hline \multirow[t]{3}{*}{ and $^{\#}$} & & & & $(0.002)$ & $(0.1)$ & $(0.03)$ & $(0.88)$ & $(0.86)$ & $(0.18)$ & $(0.55)$ & $(0.03)$ \\
\hline & \multirow{2}{*}{$\mathrm{PT}_{\mathrm{C}}$} & \multirow{2}{*}{ - } & \multirow{2}{*}{ - } & \multirow{2}{*}{1} & 0.003 & -0.1 & $-.20^{*}$ & 0.003 & -0.08 & -0.05 & 0.11 \\
\hline & & & & & $(0.98)$ & $(0.27)$ & $(0.03)$ & $(0.97)$ & $(0.39)$ & $(0.61)$ & $(0.26)$ \\
\hline \multirow[t]{6}{*}{ A } & \multirow{2}{*}{$N A_{F}$} & \multirow{2}{*}{ - } & \multirow{2}{*}{ - } & \multirow{2}{*}{ - } & \multirow{2}{*}{1} & $.59^{* *}$ & 0.06 & $.20^{*}$ & 0.07 & 0.15 & 0.15 \\
\hline & & & & & & $(<.001)$ & $(0.57)$ & $(0.03)$ & $(0.48)$ & $(0.11)$ & $(0.12)$ \\
\hline & \multirow{2}{*}{$N A_{M}$} & \multirow{2}{*}{ - } & \multirow{2}{*}{-} & \multirow{2}{*}{ - } & \multirow{2}{*}{ - } & \multirow{2}{*}{1} & 0.04 & 0.11 & 0.09 & 0.06 & 0.03 \\
\hline & & & & & & & $(0.64)$ & $(0.25)$ & $(0.33)$ & $(0.54)$ & $(0.76)$ \\
\hline & \multirow{2}{*}{$\mathrm{NT}_{\mathrm{C}}$} & \multirow{2}{*}{-} & & & & & 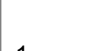 & 0.14 & 0.01 & 0.1 & 0.01 \\
\hline & & & & & . & & $r$ & $(0.15)$ & $(0.9)$ & $(0.3)$ & $(0.88)$ \\
\hline & & & & & & & & & 0.14 & $.22^{*}$ & 0.08 \\
\hline H\# & $100 \mathrm{~F}$ & 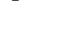 & & & 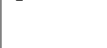 & & & & $(0.14)$ & $(0.27)$ & $(0.43)$ \\
\hline & & & & & & & & & & 0.12 & $.48^{\star *}$ \\
\hline & FSS & - & - & - & - & - & - & - & 1 & $(0.19)$ & $(<.001)$ \\
\hline & & & & & & & & & & & $.27^{\star \star}$ \\
\hline $\mathbf{A}^{\text {册m }}$ & $S T A I_{F}$ & - & - & - & - & - & - & - & - & 1 & $(0.005)$ \\
\hline & $S T A I_{M}$ & - & - & - & - & - & - & - & - & - & 1 \\
\hline
\end{tabular}

Table 1: Pearson Correlation Matrix (r) of the Variables of Interest. Note: \# PT: Positive Thoughts, NT: Negative Thoughts, PA: Positive Attributions, NA: Negative Attributions; \#\#assessed with FSS - Fear Survey Schedule; \#\#\#assessed with STAI - State-Trait Anxiety Inventory; F = Father; $\mathrm{M}=$ Mother; $\mathrm{C}=\mathrm{Child}^{*} \mathrm{p}<0.05^{* *} \mathrm{p}<0.01$.

There is a significant and strong positive correlation between children's positive thoughts and mothers' positive attributions. Fathers' and mothers' attributions are positively correlated with each other, especially the negative attributions. Fathers' negative attributions are positively related to their fears. Their fears are positively related to their anxiety. Mothers' anxiety is negatively correlated with their positive attributions and positively correlated with their fear. On the other hand, mothers' anxiety is negatively correlated with father's positive attributions and positively correlated with mothers' fears and fathers' anxiety.
The estimation of the parameters of the predictive model regarding general childhood anxiety symptoms is presented in Table 2 .

\begin{tabular}{|l|l|l|l|l|}
\hline \multicolumn{5}{|c|}{$\mathbf{r 2}^{*}=\mathbf{0 . 3 2}$} \\
\hline Variables & $\boldsymbol{\beta}$ & $\boldsymbol{\beta}$ standardized & Standard-Error & $\mathbf{P}$ \\
\hline Gender & -1.37 & -0.06 & 1.78 & 0.44 \\
\hline PAF & -0.34 & -0.07 & 0.37 & 0.36 \\
\hline PAM & -0.26 & -0.06 & 0.35 & 0.46 \\
\hline
\end{tabular}


Page 6 of 11

\begin{tabular}{|l|l|l|l|l|}
\hline PTC & -0.41 & -0.16 & 0.22 & 0.06 \\
\hline NAF & -0.31 & -0.09 & 0.35 & 0.38 \\
\hline NAM & 0.5 & 0.14 & 0.32 & 0.15 \\
\hline NTC & 0.43 & 0.32 & 0.11 & $<.001$ \\
\hline FSSF & 2.17 & 0.2 & 0.9 & 0.01 \\
\hline FSSM & -1.19 & -0.2 & 0.54 & 0.03 \\
\hline STAIF & 3.24 & 0.14 & 1.95 & 0.09 \\
\hline STAIM & 4.38 & 0.24 & 1.82 & 0.01 \\
\hline
\end{tabular}

Table 2: Multiple Linear Regression with Parents' Attributions, Children's Thoughts, Fear and Anxiety of Parents. Note: ${ }^{\star} \%$ of children's General Anxiety Symptoms variability explained by the variables. PT: Positive Thoughts, NT: Negative Thoughts, PA: Positive Attributions; NA: Negative Attributions; FSS: Fear Survey Schedule; STAI: State-Trait Anxiety Inventory; $\mathrm{F}=$ Father; $\mathrm{M}=$ Mother; $\mathrm{C}=$ Child.

The model explains $32 \%$ of the variability of general anxiety symptoms in children. The statistically significant variables (with $\mathrm{p}<$ 0.10 ) were included in the final predictive model (Figure 1).

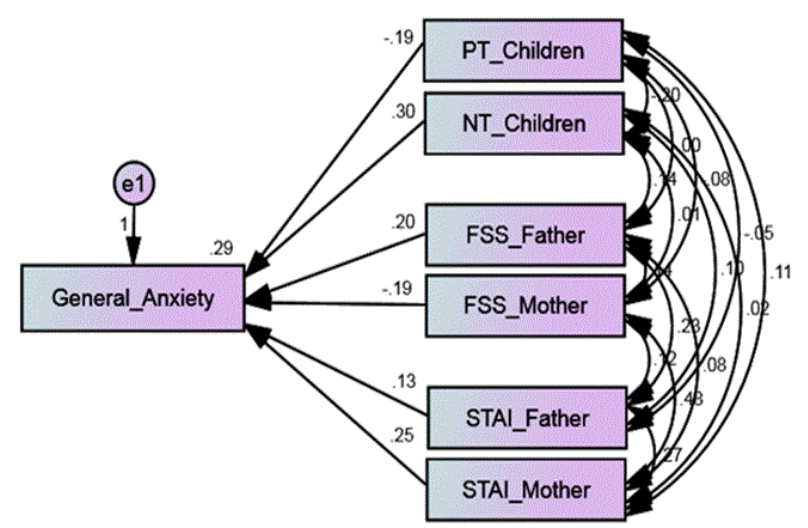

Figure 1: Predictive model of children's general anxiety symptoms.

The variables included in the final model explain $29 \%$ of the variability of general anxiety symptoms in children. The contribution of children's thoughts (PTC: $\mathrm{p}=0.021$; NTC: $\mathrm{p}<0.001$ ), parents' fears (FSSF: $\mathrm{p}=0.017$; FSSM $\mathrm{p}=0.042$ ) and mothers' anxiety (STAIF: $\mathrm{p}=$ 0.133 ; STAIM: $p=0.009$ ) to children's general anxiety is significant.

The analysis of parental interference on the difference $(\Delta)$ in children's thoughts before and after the discussion with parents is reflected in the regression models presented in Table 3. All the models reveal low predictive ability.

\begin{tabular}{|l|l|l|l|l|l|l|l|l|}
\hline & & & & $\boldsymbol{\beta}$ & $\begin{array}{l}\text { B } \\
\text { standardiz } \\
\text { ed }\end{array}$ & $\begin{array}{l}\text { Standa } \\
\text { rd- } \\
\text { Error }\end{array}$ & $\mathbf{P}$ & $\mathbf{r 2}$ \\
\hline \multirow{2}{*}{$\begin{array}{l}\text { Mode } \\
\text { I } 1\end{array}$} & $\Delta_{\text {NTCAD }}$ & $\leftarrow$ & NA $_{M}$ & 0.08 & 0.06 & 0.11 & 0.5 & \\
\cline { 2 - 9 } & $\Delta_{\text {NTCAD }}$ & $\leftarrow$ & FSS $_{M}$ & -0.03 & -0.01 & 0.24 & 0.9 & \\
\hline
\end{tabular}

\begin{tabular}{|c|c|c|c|c|c|c|c|c|}
\hline & $\Delta_{\text {NTCAD }}$ & $\leftarrow$ & $\begin{array}{l}\text { STAI } \\
\text { M }\end{array}$ & 0.14 & 0.02 & 0.74 & 0.85 & 0.004 \\
\hline \multirow{3}{*}{$\begin{array}{l}\text { Mode } \\
12\end{array}$} & $\Delta_{\text {PTCAD }}$ & $\leftarrow$ & $\mathrm{PA}_{M}$ & -0.001 & -0.001 & 0.09 & 0.99 & 0.05 \\
\hline & $\Delta_{\mathrm{PTCAD}}$ & $\leftarrow$ & $\mathrm{FSS}_{\mathrm{M}}$ & 0.27 & 0.12 & 0.15 & 0.06 & \\
\hline & $\Delta_{\mathrm{PTCAD}}$ & $\leftarrow$ & $\begin{array}{l}\text { STAI } \\
\mathrm{M}\end{array}$ & -1 & -0.23 & 0.47 & 0.03 & \\
\hline \multirow{3}{*}{$\begin{array}{l}\text { Mode } \\
13\end{array}$} & $\Delta_{\text {NTCAD }}$ & $\leftarrow$ & $N A_{F}$ & 0.1 & 0.09 & 0.12 & 0.37 & 0.02 \\
\hline & $\Delta_{\text {NTCAD }}$ & $\leftarrow$ & $\mathrm{FSS}_{\mathrm{F}}$ & 0.1 & 0.02 & 0.39 & 0.81 & \\
\hline & $\Delta_{\text {NTCAD }}$ & $\leftarrow$ & $\mathrm{STAI}_{\mathrm{F}}$ & -0.87 & -0.1 & 0.83 & 0.3 & \\
\hline \multirow{3}{*}{$\begin{array}{l}\text { Mode } \\
14\end{array}$} & $\Delta_{\mathrm{PTCAD}}$ & $\leftarrow$ & $P A_{F}$ & 0.1 & 0.1 & 0.09 & 0.27 & 0.02 \\
\hline & $\Delta_{\mathrm{PTCAD}}$ & $\leftarrow$ & $\mathrm{FSS}_{\mathrm{F}}$ & -0.3 & -0.12 & 0.24 & 0.22 & \\
\hline & $\Delta_{\mathrm{PTCAD}}$ & $\leftarrow$ & $\mathrm{STAI}_{\mathrm{F}}$ & -0.06 & -0.01 & 0.52 & 0.9 & \\
\hline
\end{tabular}

Table 3: Multiple Linear Regression of the Difference $(\Delta)$ in Children's Thoughts Before and After the Discussion of the Stories, and Parents' Attributions, Fear and Anxiety. Note: $\triangle$ NTCAD: Difference in children's negative thoughts; $\triangle \mathrm{PTCAD}$ : Difference in children's positive thoughts; PA: Positive Attributions, NA: Negative Attributions; FSS: Fear Survey Schedule; STAI: State-Trait Anxiety Inventory; F = Father; $\mathrm{M}=$ Mother

With regard to children's positive thoughts, mothers' positive attributions, fears and anxiety explain only $5 \%$ of the variance $(\mathrm{r} 2=$ 0.05) of the difference in these thoughts, which means that mothers' anxiety is a predictive variable to this difference (Model 2). When analyzing the difference in children's positive thoughts $(\triangle \mathrm{PTCAD})$ it was found that there was a decrease in the mean number of positive thoughts, even if it was not statistically significant (Before: $\mathrm{M}=3.4, \mathrm{SD}$ $=2.2$; After: $\mathrm{M}=3.3, \mathrm{SD}=2.0$; $\mathrm{t}(110)=0.521, \mathrm{p}=0.60)$. These results suggest that there is some evidence that mothers' anxiety may have contributed to the decrease of children's positive thoughts. Fathers' positive and negative attributions, their fears and anxiety did not significantly interfere in the difference found in children's positive thoughts (Model 4).

Mother's negative thoughts, fears and anxiety did not significantly influence the difference in children's negative thoughts (Model 1). Fathers' positive and negative attributions, their fears and anxiety did not significantly interfere in the children's negative thoughts (Model 3).

\section{Discussion}

The findings of the current study demonstrate the impact of children's positive and negative thoughts, and of parents' fears and mother's anxiety on children's anxiety symptoms. The children were 10 and 11 years old and came from a community sample. Overall, the results of this work contribute to the understanding of the aetiology and development of anxiety disorders during childhood.

The first goal of this study was to analyze the impact of children's positive and negative cognitions associated with ambiguous stimuli that refer to anxiety on children's anxiety symptoms. The results showed that positive and negative thoughts significantly contribute to children's anxiety. Those thoughts were composed of several contents that were verbalized by children [26] and that represented more accurately the internal representations of children [31,53]. Thus, positive and negative thoughts that are connected not only to the 
perception of presence/absence of threat in ambiguous situations, but also to emotions and (in)ability to cope or influence those situations, were explored [26] and should be considered when studying children's anxiety.

The association between anxiety and negative thoughts, including those concerning children's perceptions about their inability to cope or to influence ambiguous situations related to anxiety, is consistent with the relevant literature [12,16]. Yet, in Chorpita et al. [13], children's anxiety was related to a tendency to present anxious cognitions; the classification of that kind of cognitions (anxious/non-anxious) was not limited to the analysis of biases related to threat, but also considered biases about anxious interpretations of situations. Following that line of thought, Muris et al. [30] found that children reported an actual experience of physical symptoms related to anxiety during their life, but those symptoms were often not related to actual situations or circumstances that evoke a threat. Thus, it is important to understand anxiety beyond the biases in the interpretation of the threat presented by ambiguous situations.

The results of the current study revealed the relation and impact of negative thoughts on the anxiety symptoms of the children from this community sample. This suggests that anxiety symptoms will be more associated with normative manifestations of anxiety than with high levels of anxiety or even with anxiety disorders. Therefore, negative thoughts may underlie the development of anxiety disorders in children. This suggestion follows Creswell et al. [11] about the contribution of children's internal experiences to the development of anxiety disorders in children. Thus, negative thoughts and their features represent a vulnerability to the development of pathological anxiety in children.

Other studies also indicate that the interpretation of threat is not always found or is not strongly associated with anxiety; however, biased interpretations about the child and his/her inability to cope with the situation are always correlated with the child's anxiety $[12,16]$. In this sense, Creswell and O'Connor [14] state that "in children at this age, the concern that 'a bad thing may happen', may be less influential on the development of anxiety than the concern that 'I won't be able to cope with it"' (p. 200). The results of the current study support the need to reconsider the assessment processes (e.g. Thought-Listening), intervention strategies (e.g. focus on positive and negative thoughts and considering the importance of the expression of emotions) and even theories that concern anxiety in children.

A particular aspect of this work was the analysis of the association between children's positive thoughts and their anxiety, which is not usually done in studies that address children's cognitive characteristics related to anxiety. The results show that there is a significant negative contribution of positive thoughts to the anxiety symptoms presented by children (i.e. to the reduction of these symptoms). These results are in line with Valadão Dias et al. [26] that suggest that these kinds of thoughts are important cognitive aspects to buffer against anxiety, its beginning and maintenance.

The results of this study also contribute to a better understanding of children's cognitive characteristics related to anxiety, being this need widely described in literature $[9,17]$, because the thoughts constructed and presented by children are the product of their interpretation of ambiguous stimuli $[10,17]$. Doubts presented in literature $[10,18]$ concerning the inclusion of positive thoughts in theoretical models of childhood anxiety were clarified in this study. It was concluded that positive and negative thoughts should be considered individually and as a whole (i.e. with all their several contents) as previously suggested in literature $[24,31]$.

A final result about the analyses of children characteristics and their relation to children's anxiety was the non significant contribution of children's gender to child anxiety. It seems to be an inconsistent finding when compared with studies that found a relation between the child's gender and anxiety $[6,52,55,56]$. However, this relation is not causal, so gender may not be a predictor of anxiety, as in the current study. In some research these inconsistencies have been further discussed [57].

The second aim of the current study was to analyze the contribution of both parents' fear and anxiety to children's anxiety symptoms. The results revealed a significant impact of mothers' anxiety and both parents' fears on children's anxiety. Fathers' and mothers' fears and anxiety had different contributions to children's anxiety symptoms. These findings are consistent with some considerations regarding the relationship between each of the parental figures and the child [35,58,59].

In a first analysis (multiple linear regression), fathers' anxiety contributed to explain the variance in children's anxiety symptoms, when a significance level of $p<.10$ was considered. However, in the posterior analysis (i.e., the predictive final model of anxiety in children), fathers' anxiety was not predictive of children's anxiety symptoms. These results indicate that the causal relation analyzed (fathers' anxiety contributing to children's anxiety) does not represent possible characteristics of the relation between fathers' and children's anxiety. Few studies have pointed to the existence of a relation between those variables $[36,58]$. It is noteworthy that most studies focus on maternal anxiety or on parental anxiety (reflecting the combination of both parents' scores in anxiety assessment) despite the higher number of mothers included in the samples [58]. In this sense, the influence of fathers' anxiety is largely unknown.

The relation between parents' fear and anxiety found in this work confirmed that these concepts have common characteristics [53]. Nevertheless, fear and anxiety have distinctive characteristics, especially concerning the perception of immediate threat (real or perceived), which distinguishes fear, and the anticipation of a future threat, which characterizes anxiety [60-62]. The distinctive characteristics of fear and anxiety along with the results of this study, namely the fact that fathers' fears (but not anxiety) are predictive of children's anxiety, suggest that there are different patterns of relation between children's' anxiety and fathers' fear and anxiety.

The interpretation of these results must consider fear and anxiety features and the psychosocial and cultural aspects related to these emotions. Stereotypes have a strong implicit prescriptive aspect and maintain the cultural norms that define how, when and where men and women can display their emotions [32]. Breaking the stereotypes leads to social rejection and discrimination [32]. In this sense, the different pattern of expression of emotions for men and women may be considered an adaptive mechanism that contributes to the successful implementation of gender rules. The social construction of the image of men is based on attributions, like the focus on their physical strength and on their ability to protect the family [47,48], which are associated with their role of economic providers; these attributions persist over time [48,63]. Given the typical idea that men have more power and status [63] and the idea that fear is associated with a lack of power [64], it is more expected that women will display fear. Therefore, the display or acknowledgement of fears suggests the existence of a vulnerability that cannot be attributed to men. Still, it is well known 
that fear is a common emotion that is experienced by the individual over the life course [65]; it is an intense emotion by its feature of imminent threat, and it is hard to control by the individual or is even incontrollable (American Psychiatric Association, 2013).

Following this perspective, it could be hypothesized that fathers' psychosocial and cultural tendency to inhibit fear or to deny it could negatively limit the development of skills to deal with fear features and to control it, as denial prevents the proper knowledge and management of fear. Thus, a possible construction of "psychological and/or behavioral filters" to show fear would be compromised. As a consequence, when men's fear "comes out", its expression and experience are not elaborate. The individual may display emotions by emotional expression, i.e. observable changes in the person's face, voice, body, etc., and through emotional experiences, i.e. an evaluative and interpretative process that includes the interpretation of internal states, behavior of others, context, and meaning given by culture. Emotional experiences take the linguistic form of "I am afraid" [32].

Considering the aspects associated with a poor development of those "filters" along with the child's (socially constructed) perspective about the father as a strong and protective figure, who has no fears, it can be expected that if children perceive or observe fathers' manifestations of fear, they will develop or reinforce worries and a sense of insecurity. This seems to be a consistent explanation for the results found in this study and for the understanding of the contribution of paternal fear to children's anxiety.

The hypothesis regarding the psychosocial and cultural factors may also explain the different patterns of influence of mothers' and fathers' fears on children's anxiety. In this sense, these patterns may be related to certain expectations about mothers' and fathers' fear and roles in parenting $[48,66]$. Women are believed to be emotionally more intense, expressive, but also as having more skills to use non-verbal signs related to emotion [63]. Some stereotypes suggest that women feel several emotions, such as fear, and their expression and experience is acceptable and expected [63]. By assuming their fears, women most likely have a further knowledge about them and develop strategies to control their expression and experience. This proposal includes considerations about women and their skills to understand and manage emotion [63].

Thus, it is also possible to suggest the existence of a protector maternal mechanism that functions as a buffer against the development or maintenance of anxiety in children. The more fear mothers have, the more familiar they become with their characteristics, the more they develop their skills to manage the expression and experiences of fear. Therefore, in situations of fear, the mother may teach to the child how to live fear in a controlled manner, which will promote the reduction of the child's anxiety. This possibility is also in line with Muris et al. [57] that indicates that the relation between parents' fears and children's fears depends on the expression or absence of expression of parents' fears.

The non-predictive factor of father's anxiety and the predictive factor of mother's anxiety to the children's anxiety also support the psychosocial and cultural considerations previously presented, being their understanding associated with the fact that anxiety is a diffuse emotion related to an anticipated worry (American Psychiatric Association, 2013). Some parental aspects may enhance the influence of parents' anxiety on children's anxiety. Some specific characteristics of the sample, namely the experience of parents in marital life (in all families, the child's mother and father lived together), fathers' and mothers' roles considering their different focus on professional course and its influence on parenting are aspects to consider when understanding the relation between parents' anxiety and children's anxiety.

In the latest years, the marital relationship, which is characterized by the association of two individuals who are autonomous in terms of rights and duties, that aims to promote family well- being [66], has been associated with undifferentiated roles of men and women. However, in practical terms, performances are different [66], as women still invest more in the family dimension while men invest more on their careers $[66,67]$. Then, it would be interesting to analyze if these paternal characteristics reduce the proximity between the father and the child, because the anxiety characteristics are particularly associated with a spectrum of anticipated worries, and the perception and share of anxiety experiences possibly depend on the existence of a "proximity space" between the father and the child.

Following this line of thought, the results that show a significant contribution from mother's anxiety to children's anxiety are congruent with the previous reflection. Women's role is still more oriented to family life than men's $[48,66]$, which promotes the existence of the "proximity space" where children possibly perceive and share mothers' anxiety experiences. Unlike fear characteristics, anxiety features enhance worry and anticipation of negative and/or threatening situations, being difficult to control their signs and manage the underlying emotion. In this sense, children are vulnerable to their mothers' anxiety.

The results of the current study also show that parents' attributions are not predictive of child anxiety symptoms. This study analyzed only the parental attributions, which means that parents' thoughts about what the child may think do not predict children's anxiety. However, a significant relation between mothers' positive attributions and children's positive cognitions was found. Bögels et al. [41] analyzed the relation between parents' negative attributions and children's negative cognitions and found that children's cognitions were significantly associated with mothers' negative attributions and non-significantly related to fathers' negative attributions. The results of the current study are not consistent with those findings. Most studies have analyzed the relation between children's negative cognitions and parents' negative cognitions using parents' expectations and not their attributions $[14,68]$ or using parents' cognitions related to ambiguous stimuli that describe anxiety situations for adults $[39,40]$.

Some results found on the current work do not reveal causal relations, so caution must be taken when interpreting them, and the psychosocial and cultural aspects previously described should also be considered. As women/mothers have a higher ability to understand and manage emotions [63] they may not verbalize their negative emotional experiences to their children as well as their insecurity concerning their children's ability to cope with situations. So, mothers would share more their positive attributions than the negative ones with their children. However, the deficit in terms of fathers' "filters" would promote a positive relation between their negative attributions and children's negative cognitions, but these results were not found. Nevertheless, there were no significant relations between fathers' attributions, both positive and negative, and children's cognitions, suggesting that men may actually be investing more on their careers. This suggests that some aspects of their relationship with children are still mediated by mothers. On the other hand, it may be hypothesized that fathers' own cognitions or their expectations about the child reveal some aspects of the relationship that attributions have not addressed. 
It is also pertinent to discuss the results that indicate the existence of significant associations between fathers' and mothers' attributions, being negative attributions more strongly correlated. These results seem to support the existence of a maternal protective factor, as mothers' attributions are associated with children's positive cognitions. Interestingly, fathers and mothers seem to share their negative attributions with each other, but they do not convey them to their children. This suggests that fathers and mothers form a dynamic system in the way they influence their children [58].

Finally, the contribution of parents' fears, anxiety and attributions to the difference found in children's thoughts before and after the discussion with parents was analyzed. There was only a difference regarding positive thoughts, and this was a small and non-significant difference. However, if mothers' ability to manage emotion and anxiety characteristics are considered, it could be suggested that mothers' anxiety may negatively influence children's positive cognitions (i.e. reduces them). And once those cognitions are important cognitive aspects to buffer against anxiety, their reduction could represent a vulnerability factor. This process may represent a mechanism of negative indirect influence of mothers' anxiety over children's anxiety, which means that mothers' anxiety may contribute to model children's anxiety [35]. According to Bögels and Brechman-Toussaint [43], evidence concerning parental modelling of the development of anxiety in children is minimal.

Some limitations of the current study should be discussed. First, the sample was not representative of the Portuguese population, but the large number of participants grants some confidence to the study findings. However, the participants came from a community population, so the results may not be generalized to other populations, for example, families with one of the elements (Child, Mother and Father) having an anxiety disorder. It should also be noted that the present study analyzed normative levels of anxiety symptoms and normative anxious cognitions rather than clinical issues. The aim of the study was to investigate the causes of child anxiety and, in this sense; data from a normative sample enables a reliable assessment of the variables. However, the assessment of children's anxiety symptoms and parents' own fear and anxiety was only made through self-report questionnaires, which means that the interpretation of these results must be careful.

Another aspect that could be considered a limitation was the use of content analysis due to the subjectivity that may be implied when categorizing children's thoughts and parents' attributions. Even so, previous work [24] has demonstrated the validity of the quotation criteria with intra-correlation coefficients (ICC) above .90. This type of analysis considered the children's thoughts and parent's attributions and granted access to important information that has not been covered in studies that address the cognitive features related to anxiety. Finally, the emotional expression and the emotional experiences of parents' fear or their absence were not evaluated, so it is not possible to confirm them, but only to take into account the presented suggestions.

Although the findings of this study present some theoretical issues, they seem to be in line with previous studies which results have revealed inconsistencies in the relation between anxiety and the biased interpretation of threat. It seems that anxiety in children goes beyond fear. The results of this study and of other child anxiety investigations have shown that the constructs of fear and anxiety should be reassessed, in order to clarify their common features, but also to point to their differences. The readjustment of these constructs should also consider their relation with their normative form vs. their pathological form. Therefore it is important to clarify the variables involved in child anxiety, including parental variables, their fears, their anxiety, and the relation of these aspects with parents' cognitions, expectations, attributions, modelling processes, parenting styles and other variables described in the literature. For example, parenting styles may have different relations with parent's fears and anxiety patterns. It is also possible that the perception of the child about his/her parents' parenting styles is influenced by the child's perception about parents' fears and anxiety. In conclusion, the independent analysis of these two constructs and their independent relation with other variables may contribute to knowledge in the field of child anxiety. The findings of this study point to multiple aspects that could be investigated to further understand child and parental factors that contribute or even predict higher levels or pathological levels of anxiety in children. Further research should analyze other children's variables, such as their beliefs and the parental contribution to their origin; child's selfesteem and its contribution to anxiety and to the construction of negative beliefs. Future research should also address the variables that may function as buffers against anxiety.

This study and its methodology brought important information to the theoretical understanding of children's anxiety by the analysis of several child and parental variables. It also proposed a new perspective of analysis, which is based on the knowledge about children's normative development and the child's individual perspective, instead of referring to adult theories. The results and discussion of the present work contribute to the understanding of some protective factors which may prevent pathological child anxiety. Early intervention and prevention have been consistently acknowledged in literature as essential [68]. For example, a study developed by de Matos et al. [6] with a representative Portuguese sample has shown that children aged between 10 and 13 had fewer anxiety and depressive symptoms when compared with older children. The results also demonstrated that the older the children were, the higher the anxiety and depression levels. The authors stressed the importance and need for early interventions and the development of intervention programs to prevent or at least reduce the onset of depression and anxiety in adolescence [6].

Some intervention programs/strategies can be delineated using the information provided by this study, for example: (1) the implementation of re-education programs with both parents aiming at the promotion of positive thoughts, as they can protect against the development of anxiety, (2) also the re-education of child's beliefs providing specific situations where children can accurately evaluate their capabilities and learn how to use them, and (3) intervention groups with children aiming at understanding the ideas that underlie child's beliefs. All these strategies can be used with preventive purposes and at the clinical level, as long as they are adapted to the corresponding contexts $[69,70]$.

\section{Acknowledgements}

We kindly acknowledge the Portuguese Foundation for Science and Technology (FCT) for providing grant SFRH/BD/63377/2009.

\section{References}

1. Albano AM, Causey D, Carter B (2001) Fear and anxiety in children.

2. Craske MG (1997) Fear and anxiety in children and adolescents. Bull Menninger Clin 61: A4-36.

3. Gullone E (2000) The development of normal fear: a century of research. Clin Psychol Rev 20: 429-451. 
4. Stallard P (2009) Anxiety: Cognitive behaviour therapy with children and young people. NY US: Routledge/Taylor \& Francis Group.

5. Cartwright-Hatton S, McNicol K, Doubleday E (2006) Anxiety in a neglected population: Prevalence of anxiety disorders in pre-adolescent children. Clin Psychol Rev 26: 817-833.

6. de Matos MG, Barrett P, Dadds M, Shortt A (2003) Anxiety, depression, and peer relationships during adolescence: Results from the Portuguese national health behaviour in school-aged children survey. European Journal of Psychology of Education 18: 3-14.

7. Cartwright-Hatton S (2006) Anxiety of childhood and adolescence: Challenges and opportunities. Clin Psychol Rev 26: 813-816.

8. Velting ON, Setzer NJ, Albano AM (2004) Update on and advances in assessment and cognitive-behavioral treatment of anxiety disorders in children and adolescents. Professional Psychology: Research and Practice 35: 42-54.

9. Field AP, Cartwright-Hatton S, Reynolds S, Creswell C (2008) Future directions for child anxiety theory and treatment. Cognition and Emotion 22: 385-394.

10. Prins PJM (2001) Affective and cognitive processes and the development and maintenance of anxiety and its disorders.

11. Barrett P, Rapee R, Dadds M, Ryan S (1996) Family enhancement of cognitive style in anxious and aggressive children. Journal of Abnormal Child Psychology 24: 187-203.

12. Bögels SM, Zigterman D (2000) Dysfunctional cognitions in children with social phobia, separation anxiety disorder, and generalized anxiety disorder. J Abnorm Child Psychol 28: 205-211.

13. Chorpita BF, Albano AM, Barlow DH (1996) Cognitive processing in children: Relation to anxiety and family influences. Journal of Clinical Child Psychology 25: 170-176.

14. Creswell C, O'Connor TG (2011) Interpretation bias and anxiety in childhood: Stability, specificity and longitudinal associations. Behav Cogn Psychother 39: 191-204.

15. Hadwin JA, Garner M, Perez-Olivas G (2006) The development of information processing biases in childhood anxiety: A review and exploration of its origins in parenting. Clin Psychol Rev 26: 876-894.

16. Waters AM, Wharton TA, Zimmer-Gembeck MJ, Craske MG (2008) Threat-based cognitive biases in anxious children: Comparison with nonanxious children before and after cognitive behavioural treatment. Behav Res Ther 46: 358-374.

17. Alfano CA, Beidel DC, Turner SM (2002) Cognition in childhood anxiety: conceptual, methodological, and developmental issues. Clin Psychol Rev 22: 1209-1238.

18. Hogendoorn SM, Prins PJ, Vervoort L, Wolters LH, Nauta MH, et al. (2012) Positive thinking in anxiety disordered children reconsidered. J Anxiety Disord 26: 71-78.

19. Kendall PC (1985) Toward a cognitive-behavioral model of child psychopathology and a critique of related interventions. J Abnorm Child Psychol 13: 357-372.

20. Kendall PC, Treadwell KR (2007) The role of self-statements as a mediator in treatment for youth with anxiety disorders. J Consult Clin Psychol 75: 380-389.

21. Prins PJ, Hanewald GJ (1997) Self-statements of test-anxious children: thought-listing and questionnaire approaches. J Consult Clin Psychol 65: 440-447.

22. Spence SH, Donovan C, Brechman-Toussaint M (1999) Social skills, social outcomes, and cognitive features of childhood social phobia. J Abnorm Psychol 108: 211-221.

23. Treadwell KR, Kendall PC (1996) Self-talk in youth with anxiety disorders: states of mind, content specificity, and treatment outcome. J Consult Clin Psychol 64: 941-950.

24. Valadão Dias F, Oliveira R, Leal I, Maroco J (2015c) Positive and negative thoughts in ambiguous anxiety-related stories: The child's perspective. Psychology, Community \& Health 4: 53-64.
25. Muris P, Huijding J, Mayer B, Hameetman M (2008) A Space Odyssey: Experimental Manipulation of Threat Perception and Anxiety-Related Interpretation Bias in Children. Child Psychiatry Hum Dev 39: 469-480.

26. Valadão Dias F, Oliveira R, Rodrigues C, Figueiredo C, Leal I, et al. (2015d) Exploring childhood cognitions through the contents of children's thoughts when exposed to ambiguous situations related to anxiety: A qualitative approach. Clinical and Experimental Psychology.

27. Creswell C, Shildrick S, Field A (2011) Interpretation of ambiguity in children: A prospective study of associations with anxiety and parental interpretations. Journal of Child \& Family Studies 20: 240-250.

28. Muris P, Field AP (2008) Distorted cognition and pathological anxiety in children and adolescents. Cognition and Emotion 22: 395-421.

29. Muris P, Jacques P, Mayer B (2004) The stability of threat perception abnormalities and anxiety disorder symptoms in non-clinical children. Child Psychiatry Hum Dev 34: 251-265.

30. Muris P, Hoeve I, Meesters C, Mayer B (2004) Children's perception and interpretation of anxiety-related physical symptoms. J Behav Ther Exp Psychiatry 35: 233-244.

31. Warren SL, Emde RN, Sroufe LA (2000) Internal representations: Predicting anxiety from children's play narratives. J Am Acad Child Adolesc Psychiatry 39: 100-107.

32. Lewis $\mathrm{M}(2008)$ The emergence of human emotions.

33. Ginsburg GS, Schlossberg MC (2002) Family-based treatment of childhood anxiety disorders. International Review of Psychiatry 14: $143-154$

34. Last CG, Strauss CC (1989) Panic disorder in children and adolescents. Journal of Anxiety Disorders 3: 87-95.

35. Burstein M, Ginsburg GS (2010) The effect of parental modeling of anxious behaviors and cognitions in school-aged children: An experimental pilot study. Behav Res Ther 48: 506-515.

36. Cooper PJ, Fearn V, Willetts L, Seabrook H, Parkinson M (2006) Affective disorder in the parents of a clinic sample of children with anxiety disorders. J Affect Disord 93: 205-212.

37. Cobham VE, Dadds MR, Spence SH (1998) The role of parental anxiety in the treatment of childhood anxiety. J Consult Clin Psychol 66: 893-905.

38. Gifford S, Reynolds S, Bell S, Wilson C (2008) Threat interpretation bias in anxious children and their mothers. Cognition and Emotion 22: 497-508.

39. Creswell C, O'Connor TG (2006) Anxious cognitions in children: An exploration of associations and mediators. British Journal of Developmental Psychology 24: 761-766.

40. Creswell C, Schniering CA, Rapee RM (2005) Threat interpretation in anxious children and their mothers: comparison with nonclinical children and the effects of treatment. Behav Res Ther 43: 1375-1381.

41. Bögels SM, van Dongen L, Muris P (2003) Family influences on dysfunctional thinking in anxious children. Infant and Child Development 12: 243-252.

42. Muris P, Steerneman P, Merckelbach H, Meesters C (1996) The role of parental fearfulness and modeling in children's fear. Behav Res Ther 34: 265-268.

43. Bögels SM, Brechman-Toussaint ML (2006) Family issues in child anxiety: Attachment, family functioning, parental rearing and beliefs. Clin Psychol Rev 26: 834-856.

44. Fisak B, Grills-Taquechel AE (2007) Parental modeling, reinforcement, and information transfer: Risk factors in the development of child anxiety?. Clin Child Fam Psychol Rev 10: 213-231.

45. Bandura A (1977) Social learning theory. S.L: Prentice-hall.

46. Rachman S (1991) Neo-conditioning and the classical theory of fear acquisition. Clinical Psychology Review 11: 155-173.

47. Bögels SM, Perotti EC (2011) Does Father Know Best? A Formal Model of the Paternal Influence on Childhood Social Anxiety. J Child Fam Stud 20: 171-181.

48. Cabrera NJ, Tamis-LeMonda CS, Bradley RH, Hofferth S, Lamb ME (2000) Fatherhood in the twenty-first century. Child Dev 71: 127-136. 
Citation: Valadão Dias F, Campos JADB, Oliveira RV, Mendes R, Leal I, et al. (2016) Causal Factors of Anxiety Symptoms in Children. Clin Exp Psychol 2: 131. doi:10.4172/2471-2701.1000131

Page 11 of 11

49. Silva DR (2003) O Inventário de Estado-Traço de Ansiedade (S.T.A.I).

50. Muris P, Merckelbach H, Schmidt H, Mayer B (1999) The revised version of the Screen for Child Anxiety Related Emotional Disorders (SCAREDR): Factor structure in normal children. Personality and Individual Differences 26: 99-112.

51. Arrindell WA (1980) Dimensional structure and psychopathology correlates of the Fear Survey Schedule (FSS-III) in a phobic population: A factorial definition of agoraphobia. Behav Res Ther 18: 229-242.

52. Valadão Dias F, Campos JADB, Mendes R, Leal I, Maroco J (2015a) The factorial structure of the SCARED-R in a Portugues sample. Psychology, Community \& Health (in press).

53. Valadão Dias F, Leal I, Maroco J (2015b) Inventário de medos III: Avaliação das qualidades psicométricas em uma amostra Portuguesa. Psychology/Psicologia Reflexão e Crítica 28: 11-20.

54. Brislin RW (1986) The wording and translation of research instruments.

55. Essau CA, Anastassiou-Hadjicharalambous X, Muñoz LC (2013) Psychometric properties of the Screen for Child Anxiety Related Emotional Disorders (SCARED) in Cypriot children and adolescents. European Journal of Psychological Assessment 29: 19-27.

56. Muris P, Schmidt H, Merckelbach H (2000) Correlations among two selfreport questionnaires for measuring DSM-defined anxiety disorder symptoms in children: The Screen for Child Anxiety Related Emotional Disorders and the Spence Children's Anxiety Scale. Personality and Individual Differences 28: 333-346.

57. Muris P, Merckelbach H, Mayer B, Snieder N (1998) The relationship between anxiety disorder symptoms and negative self-statements in normal children. Social Behavior \& Personality: An International Journal 26: 307- 316 .
58. Bögels S, Phares V (2008) Fathers' role in the etiology, prevention and treatment of child anxiety: a review and new model. Clin Psychol Rev 28: 539-558.

59. Gallagher B, Cartwright-Hatton S (2009) The relationship between parental anxiety and child-related cognition: An experimental approach. Cognitive Therapy and Research 33: 523-531.

60. Blanchard DC, Blanchard RJ (1988) Ethoexperimental approaches to the biology of emotion. Annu Rev Psychol 39: 43-68.

61. Öhman A (2008) Fear and anxiety: Overlaps and dissociations.

62. Rosen JB, Schulkin J (1998) From normal fear to pathological anxiety. Psychol Rev 105: 325-350.

63. Brody LR, Hall JA (2008) Gender and emotion in context.

64. Stets JE, Turner JH (2008) The sociology of emotions.

65. Rachman S (2004) Fear and Courage: A Psychological Perspective. Social Research 71: 149-176.

66. Torres A (2002) Casamento em Portugal. Uma análise sociológica. Oeiras: Celta Editora.

67. Torres A, Mendes R, Lapa T (2008) Families in Europe. Portuguese Journal of Social Science 7: 49-84.

68. Creswell C, O'Connor T, Brewin CR (2006) A Longitudinal Investigation of Maternal and Child 'Anxious Cognitions'. Cognitive Therapy \& Research 30: 135-147.

69. Zimmerman $M(2013)$ What is ironic about wanting empirical support to justify changes in diagnostic criteria? Commentary on "the ironic fate of the personality disorders in DSM-5". Personal Disord 4: 352-353.

70. Zatz S, Chassin L (1985) Cognitions of test-anxious children under naturalistic test-taking conditions. J Consult Clin Psychol 53: 393-401. 